\title{
Multi-epitope templates imprinted particles for the simultaneous capture of various target proteins
}

(Supporting Information)

Kaiguang Yang, Senwu Li, Jianxi Liu, Lukuan Liu, Lihua Zhang* and Yukui Zhang (*E-mail: Lihuazhang@dicp.ac.cn)

\begin{abstract}
To achieve the simultaneous capture of various target proteins, the multi-epitope templates imprinted particles were developed by phase inversion-based polyethersulfone (PES) self-assembly. Herein, with the top three high-abundance proteins in the human plasma, serum albumin, immunoglobulin $\mathrm{G}$ and transferrin, as the target proteins, their $\mathrm{N}$-terminal peptides were synthesized as the epitope templates. After the preorganization of three epitopes and PES in dimethylacetamide, the multiepitope templates imprinted particles were formed in water through self-assembly, by which the simultaneous recognition of three target proteins in human plasma was achieved with high selectivity. Furthermore, the binding kinetics study proved that the adsorption mechanism in this imprinting system towards three epitope templates was same as that on the single-epitope imprinting polymer. These results demonstrate that our proposed multi-epitope templates imprinting strategy might open a new era of artificial antibodies to achieve the recognition of various targets.
\end{abstract}




\section{Chemicals}

Polyethersulfone (PES, Ultrason E 6020P, CAS No.:25608-63-3) was purchased from BASF chemical company (Ludwigshafen, Rhineland-Palatinate, Germany) and was used to prepare porous particles. Three epitopes, MKWVTFISL (corresponding to HSA), ASTKGPSVF (corresponding to IgG) and MRLAVGALL (corresponding to TRF) were obtained from ChinaPeptides Co., Ltd. (Shanghai, China) and used as the template. Purity of all three peptides was 98\%. N,N-dimethylacetamide (DMAc) was obtained from Tianjing Kermel Chemical Reagents Development Centre (Tianjin, China). HPLC-grade acetonitrile was purchased from Merck (Darmstadt, Germany), and 1-(3-dimethylaminopropyl)-3-ethylcarbodiimide hydrochloride (EDC), trifluoroacetic acid (TFA), dithiothreitol (DTT) and iodoacetamide (IAA) were obtained from Acros Organics (Geel, Belgium) and applied to the shotgun proteomic analysis and quantification. All reagents were of analytical reagent grade, unless otherwise specified. The water was purified using a Milli-Q system (Millipore, Milford, MA).

\section{Preparation of the multi-epitope templates imprinted particles via polymer}

\section{self-assembly}

Multi-epitope templates imprinted particles (MIPs) were prepared using the selfassembly method based on a PES phase inversion in PES/nonsolvent solution. $300 \mathrm{mg}$ PES were dissolved in $1200 \mathrm{mg}$ dimethylacetamide (DMAc). Three epitopes, MKWVTFISL (42 mg), ASTKGPSVF (10 mg) and MRLAVGALL (4 mg), were employed as templates and dispersed in PES solution. The amount of the three epitopes corresponded to the ratio of the top three high-abundance proteins, HSA, IgG and 
Transferrin, in human plasma. The resultant polymer solution was added dropwise to the distilled water using a $0.6-\mathrm{mm}$ diameter needle at room temperature to fabricate the multi-epitope templates imprinted particles via phase inversion. These particles were then incubated in water over $24 \mathrm{~h}$ to remove DMAc from the microspheres. The particles were prepared after the exchange between solvent and nonsolvent was com-

pleted. Finally, the templates were extracted from the solidified polymers by washing them with a mixture of methanol/acetic acid $(\mathrm{v}: \mathrm{v}=9: 1)$ at $40^{\circ} \mathrm{C}$ until no epitope peaks could be detected at $\mathrm{m} / \mathrm{z}=1124,893$ and 943 by MALDI-TOF MS. Simultaneously, non-imprinted PES particles (NIPs) were prepared with 20 wt \% PES solution in the same manner, but without the addition of the templates.

\section{Morphology}

The beads were dried at room temperature prior to SEM observation. For the crosssections morphology study, the beads were then quenched with liquid nitrogen, cut with a single-edged razor blade, attached to the sample supports and coated with a gold layer. Zeiss SUPER 55 (Oberkochen, Germany) was used for morphological analysis. For the morphology studies to intact mircospheres and their surfaces, the beads were attached to the sample supports and coated with a gold layer, analysed by FEI Quanta 200F (Hillsboro, US).

The non-imprinted PES particles (NIPs) were found in Figure S-1 (a-d). 


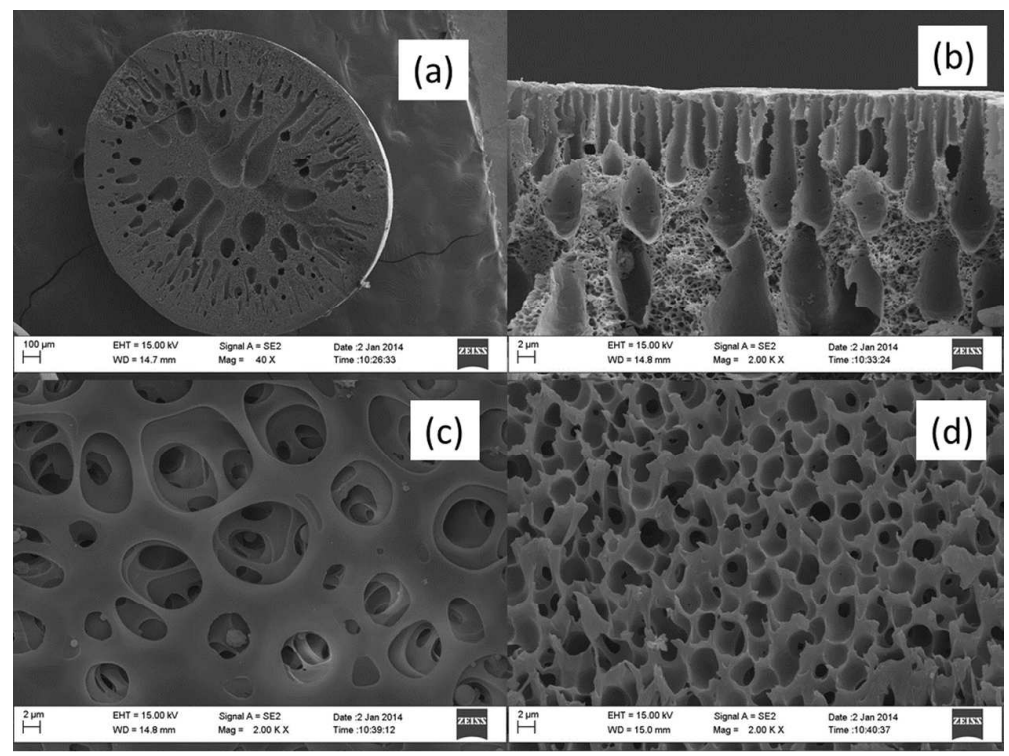

Figure S-1. SEM photographs of the cross-sections of NIPs: entire particle (a), skin layer (b), interpenetrated channel (c) and porous internal structure (d).

The SEM photographs of the intact particles and their surfaces were found in Figure S-2 (a-d).
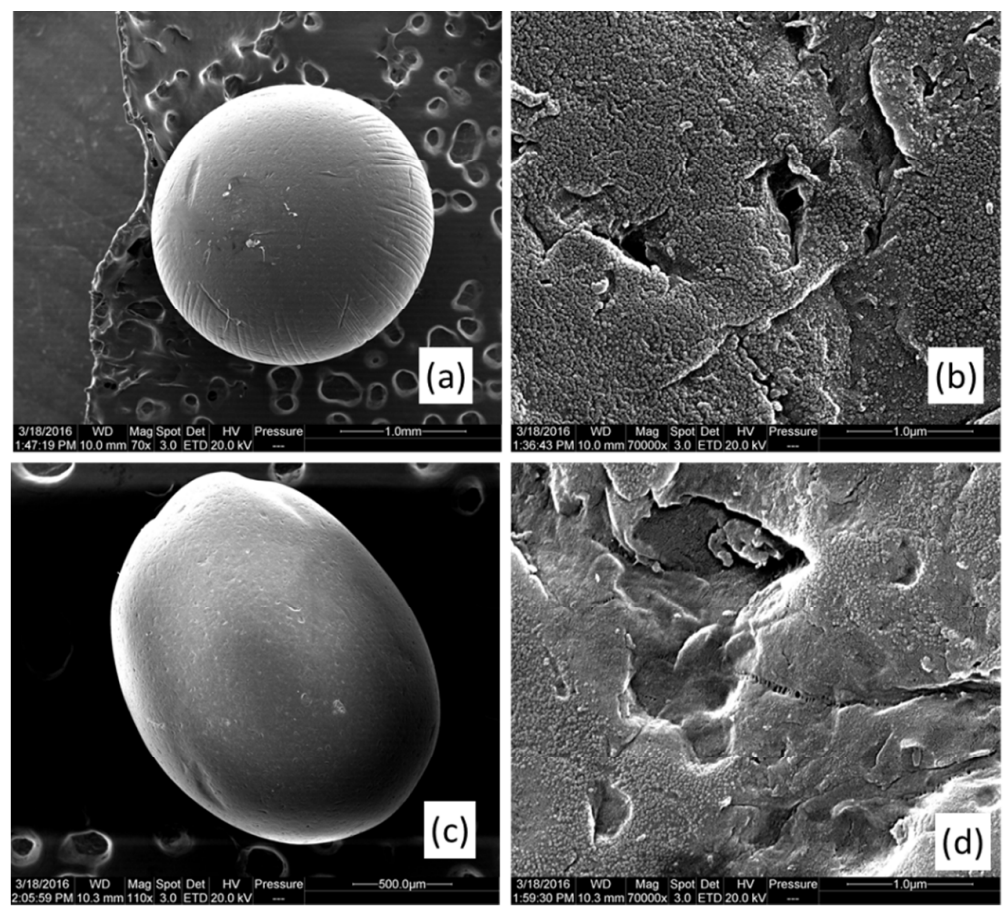
Figure S-2. SEM photographs of the intact NIPs (a) and its surface (b); SEM photographs of the intact MIPs (c) and its surface (d).

\section{Drying loss measurements}

Diameter and porosity of the particles were calculated from the density of the polymer and the change in the sample weight with drying, or the drying loss measurements, using the following two equations: ${ }^{1}$

$$
\begin{aligned}
& \text { Diameter }=\left[\frac{6\left[\mathrm{~W}_{\mathrm{A}} / \rho_{\mathrm{P}}+\left(\mathrm{W}_{\mathrm{B}}-\mathrm{W}_{\mathrm{A}}\right) / \rho_{\mathrm{W}}\right]}{\pi}\right]^{1 / 3} \\
& \text { Porosity }=\frac{\left(\mathrm{W}_{\mathrm{B}}-\mathrm{W}_{\mathrm{A}}\right) / \rho_{\mathrm{W}}}{\mathrm{W}_{\mathrm{A}} / \rho_{\mathrm{P}}+\left(\mathrm{W}_{\mathrm{B}}-\mathrm{W}_{\mathrm{A}}\right) / \rho_{\mathrm{W}}} \times 100 \%
\end{aligned}
$$

where $\mathrm{W}_{\mathrm{B}}$ is the weight of the sample before drying in $\mathrm{g}$; $\mathrm{W}_{\mathrm{A}}$ is the weight of the sample in $\mathrm{g}$ after drying; $\rho_{\mathrm{W}}$ is the density of water equal to $1.0 \mathrm{~g} / \mathrm{cm}^{3}$; and $\rho_{\mathrm{P}}$ is the density of the polyethersulfone, which is equal to $1.43 \mathrm{~g} / \mathrm{cm}^{3}$.

To calculate diameter and porosity, the experiments were conducted in triplicate with 10 stochastic particles included in each experiment.

\section{Adsorption kinetics}

To evaluate the recognition abilities of multi-epitope templates imprinted particles, 8 MIPs and NIPs were separately incubated with $\mathrm{E}_{\mathrm{HSA}}, \mathrm{E}_{\mathrm{IgG}}$ and $\mathrm{E}_{\mathrm{TRF}}$ in aqueous solutions with the initial epitope concentration of $0.25 \mathrm{mg} / \mathrm{mL}$ at $20^{\circ} \mathrm{C}$. After incubation at different time intervals, the concentration of the residual epitopes was mixed with an 
artificial synthesized peptide (APGDRIYVHPF; Mw=1271.4; concentration after mixture: $25 \mu \mathrm{g} / \mathrm{mL}$ ) as the internal standard for the measurement on the MALDI-TOF MS. In the MALDI-TOF MS detection, the peak area ratio of the target peptide to internal standard peptide was obtained to indicate the template concentration. The template quantities bound to the imprinted and non-imprinted particles, $[\mathrm{S}]_{\text {(imprinted) }}$ and $[\mathrm{S}]_{\text {(non-imprinted) }}(\mathrm{mg} / \mathrm{g})$, were calculated using the following equation:

$$
[\mathrm{S}]_{\text {(imprinted) or (non-imprinted) }}=\left(\mathrm{C}_{0}-\mathrm{C}_{\mathrm{t}}\right) \mathrm{V} / \mathrm{W}
$$

where $\mathrm{C}_{0}$ and $\mathrm{C}_{\mathrm{t}}$ are the template concentrations $(\mathrm{mg} / \mathrm{L})$ in the solutions measured initially and after an interval, time t, respectively. The volume of the incubation solution is $\mathrm{V}(\mathrm{L})$, and $\mathrm{W}(\mathrm{g})$ is the weight of the dry PES particles.

The recognition factor $(\alpha)$ was used to evaluate recognition ability, which was defined as follows:

$$
\alpha=[\mathrm{S}]_{(\text {imprinted })} /[\mathrm{S}]_{(\text {non-imprinted) }} .
$$

For MIPs adsorption toward $\mathrm{E}_{\mathrm{HSA}}, \mathrm{E}_{\mathrm{IgG}}$ and $\mathrm{E}_{\mathrm{TRF}}$, the second-order kinetic model was used to fit the adsorption kinetics (Figure 2). And, the detailed constants were listed in Table S-1.

Table S-1. The constants of second-order rate equation of Lagergren kinetic model toward MIPs adsorption of $\mathrm{E}_{\mathrm{HSA}}, \mathrm{E}_{\mathrm{IgG}}$ and $\mathrm{E}_{\mathrm{TRF}}$.

\begin{tabular}{|l|c|c|c|}
\hline Targets & $\mathbf{E}_{\text {HSA }}$ & $\mathbf{E}_{\mathrm{IgG}}$ & $\mathbf{E}_{\mathrm{TRF}}$ \\
\hline $\mathbf{v}_{\mathbf{0}}\left(\mathrm{mg} \mathrm{g}^{-1} \mathbf{h}^{-1}\right)^{*}$ & 2.361 & 18.657 & 7.831 \\
\hline $\mathbf{Q}_{\mathbf{e}}\left(\mathrm{mg} \mathrm{g}^{-1}\right)^{*}$ & 12.887 & 57.471 & 13.755 \\
\hline $\left.\mathbf{k}_{\mathbf{2}}\left(\mathrm{mg} \mathrm{g} \mathrm{h}^{-1}\right)^{-1}\right)^{*}$ & 0.0142 & 0.00565 & 0.0414 \\
\hline
\end{tabular}

${ }^{*} Q_{e}\left(\mathrm{mg} \mathrm{g}^{-1}\right)$ are the final equilibrium adsorption capacity; $v_{0}\left(\mathrm{mg} \mathrm{g}^{-1} \mathrm{~h}^{-1}\right)$ is the initial adsorption rate; and $k_{2}\left(\mathrm{~g} \mathrm{mg}^{-}\right.$ ${ }^{1} \mathrm{~h}^{-1}$ ) represents the rate constant of second-order adsorption. 
For NIPs adsorption toward $\mathrm{E}_{\mathrm{HSA}}, \mathrm{E}_{\mathrm{IgG}}$ and $\mathrm{E}_{\mathrm{TRF}}$, the second-order kinetic model was used to fit the adsorption kinetics (Figure S-3). Compared with correlation factors calculated for MIPs, those for NIPs were relatively low at $0.961,0.907$ and 0.772 for $\mathrm{E}_{\mathrm{HSA}}, \mathrm{E}_{\mathrm{IgG}}$ and $\mathrm{E}_{\mathrm{TRF}}$, respectively.

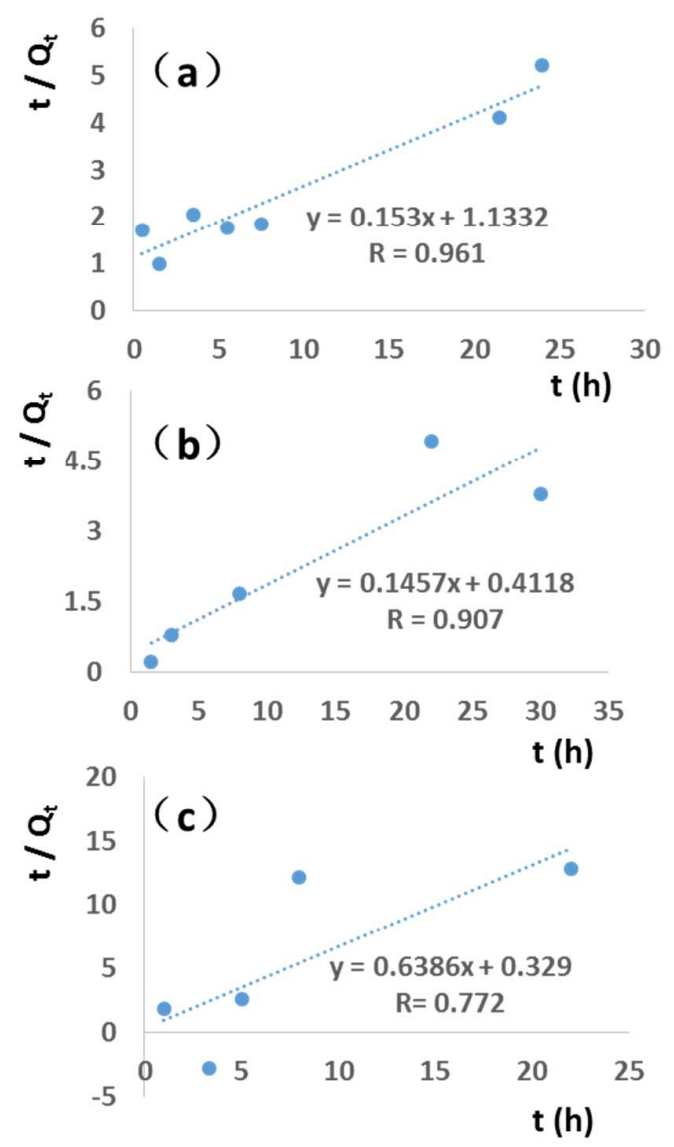

Figure S-3. Curve of second-order rate equation of Lagergren kinetic model toward NIPs adsorption of $\mathrm{E}_{\mathrm{HSA}}(\mathrm{a}), \mathrm{E}_{\mathrm{IgG}}(\mathrm{b})$ and $\mathrm{E}_{\mathrm{TRF}}(\mathrm{c})$.

\section{Equilibrium adsorption}

To study the binding isotherm of multi-epitope templates imprinted particles, 4 MIPs $(3.5 \mathrm{mg})$ and 4 NIPs $(7.2 \mathrm{mg})$ particles were separately incubated with $\mathrm{E}_{\mathrm{HSA}}, \mathrm{E}_{\mathrm{IgG}}$ and $\mathrm{E}_{\mathrm{TRF}}$ in aqueous solutions with the various epitope concentrations $(50 \mu \mathrm{g} / \mathrm{mL}, 100$ $\mu \mathrm{g} / \mathrm{mL}, 200 \mu \mathrm{g} / \mathrm{mL}, 300 \mu \mathrm{g} / \mathrm{mL}, 400 \mu \mathrm{g} / \mathrm{mL}$ ) at $20^{\circ} \mathrm{C}$. Incubation time was fixed at 48 
$\mathrm{h}$ for the equilibrium adsorption. After incubation, the supernatant epitopes were mixed with an artificial synthesized peptide (AASQAALGL; Mw=800.9; concentration after mixture: $250 \mu \mathrm{g} / \mathrm{mL}$ ) as the internal standard for the measurement on the MALDI-TOF MS. In the MALDI-TOF MS detection, the peak intensity ratio of the target peptide to internal standard peptide was obtained to indicate the template concentration. The template quantities bound to the imprinted and non-imprinted particles, $[\mathrm{S}]_{(\text {imprinted) }}$ and $[\mathrm{S}]_{(\text {non-imprinted) }}(\mathrm{mg} / \mathrm{g})$, were calculated using the above-mentioned equation (3).
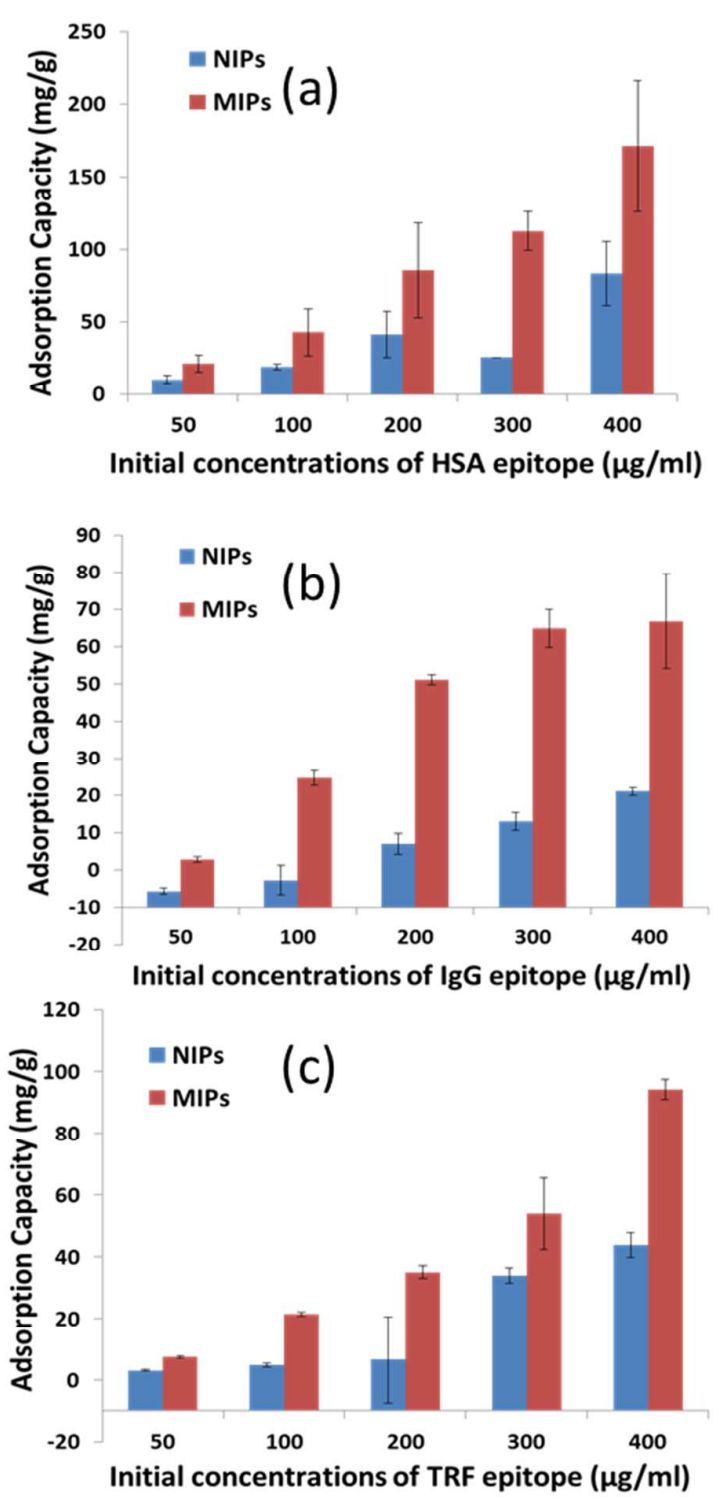
Figure S-4. Equilibrium adsorption of multi-epitope templates imprinted particles and nonimprinted particles (NIPs) towards HSA epitope (a), IgG epitope (b) and TRF epitope (c). Incubation volume: $1.5 \mathrm{~mL}$; sample concentrations: $50 \mu \mathrm{g} / \mathrm{mL}, 100 \mu \mathrm{g} / \mathrm{mL}, 200 \mu \mathrm{g} / \mathrm{mL}, 300 \mu \mathrm{g} / \mathrm{mL}, 400 \mu \mathrm{g} / \mathrm{mL}$; incubation time: $48 \mathrm{~h}$. All data represent the mean values of three parallel incubations. All error bars represent the standard error.

As shown in Figure S-4, the adsorption capacity of MIPs towards HSA epitope, IgG epitope, and TRF epitope increased separately with the increase of each epitope concentrations. At each concentration, the adsorption capacity of MIP was higher than that of NIPs, indicating that the imprinted sites promoted the high specific affinity towards their respective targets.

\section{Selectivity test in the protein mixture}

Selectivity test was carried out with three target protein (HSA, IgG and TRF) and interfering protein (Cytochrome c (Cyc)). 8 MIPs (0.007 g) and 8 NIPs (0.0144g) were incubated with $3 \mathrm{ml}$ standard protein mixture with $0.3125 \mathrm{mg} / \mathrm{ml}$ for each protein at $4{ }^{\circ} \mathrm{C}$ for $25.5 \mathrm{~h}$. Concentrations of protein in the supernatant were measured by HPLC with a diode array detector (Chromaster HPLC, Hitachi High-Tech). In detail, a home-made C8 column $(4.6 \times 150 \mathrm{~mm}, 5 \mu \mathrm{m}, 200 \AA)$ was used for the separation of proteins. 5\% (V/V) ACN with 0.1\% (V/V) TFA (mobile phase A) and 95\% (V/V) ACN with $0.1 \%(\mathrm{~V} / \mathrm{V})$ TFA (mobile phase B) were employed to generate a gradient of $0 \%$ to $60 \%$ mobile phase B within $18 \mathrm{~min}$ at a flow rate of $1 \mathrm{ml} / \mathrm{min}$. All proteins were detected at $214 \mathrm{~nm}$. 
The protein quantities bound to the MIPs and NIPs were calculated by the concentration differences between the initial concentrations and the supernatant concentrations. The binding capacity was in the unit of \%/g. As shown in Figure S-5, multiepitope templates imprinted particles show obvious recognition ability towards the target proteins, HSA and TRF.

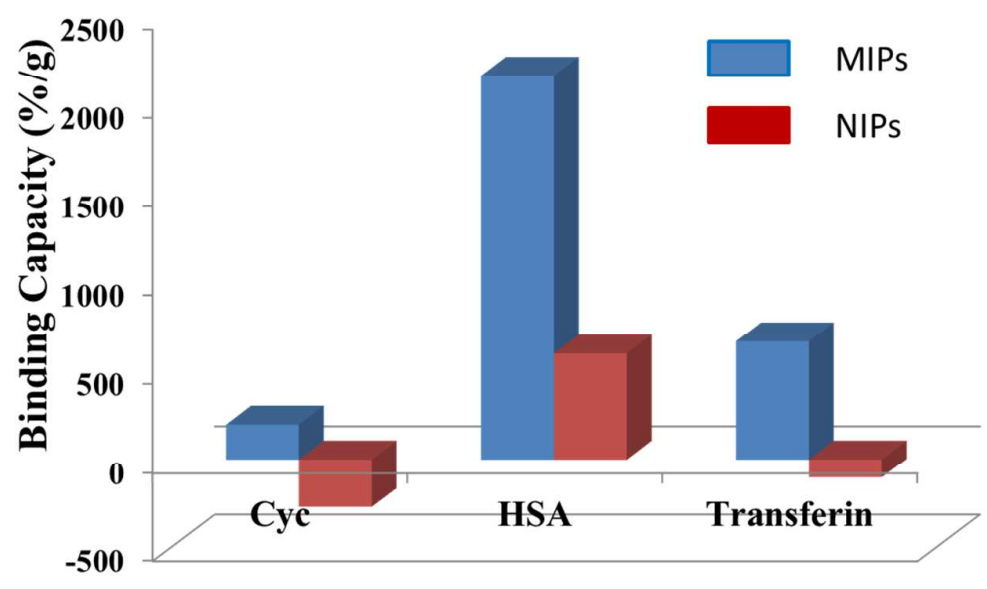

Figure S-5. Adsorption capacity of multi-epitope templates imprinted particles toward Cyc, HSA and TRF from mixed protein solution of Cyc, HAS, TRF and IgG (1:1:1:1). Incubation conditions: incubation sample: mixed protein solution contain $0.3125 \mathrm{mg} / \mathrm{ml}$ for each protein; amount of MIPs and NIPs: 8 particles; incubation volume: $3 \mathrm{~mL}$; incubation time: $25.5 \mathrm{~h}$.

It should be mentioned that $\operatorname{IgG}$ could not be detected on the chromatography (Figure S-6), although we optimized the chromatographic gradient for long time. We deduce that the IgG was trapped by the $\mathrm{C} 8$ chromatographic column. But, in the following real sample detection shown in Figure 3, the $\operatorname{IgG}$ could be detected by the mass spectrometry. This result also demonstrated that IgG could be recognized selectively by the MIPs in the protein mixture. 


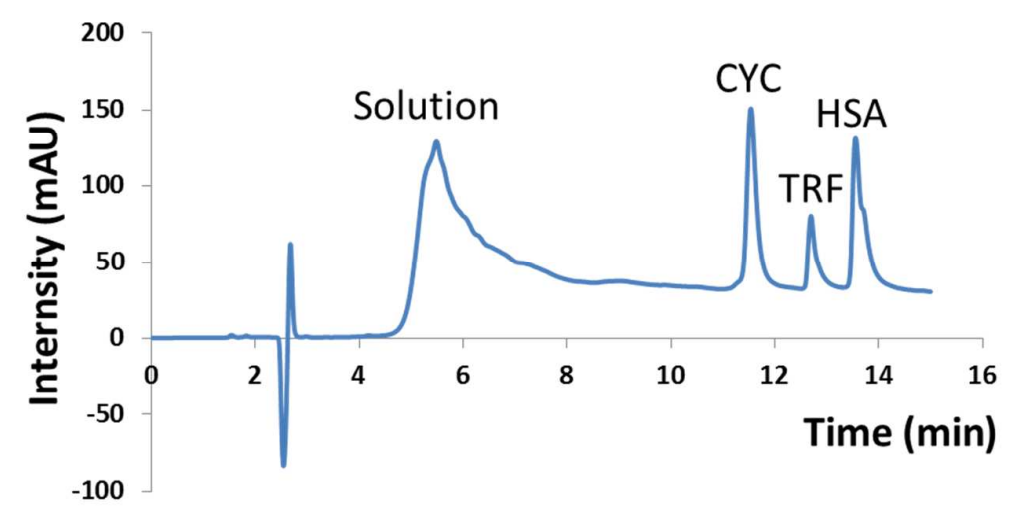

Figure S-6. Chromatographic separation of protein mixture of Cyc, HAS, TRF and IgG (1:1:1:1). Experimental conditions: Concentrations of protein were measured by HPLC with a diode array detector (Chromaster HPLC, Hitachi High-Tech). In detail, a home-made C8 column $(4.6 \times 150 \mathrm{~mm}$, $5 \mu \mathrm{m}, 200 \AA$ ) was used for the separation of proteins. $5 \%$ (V/V) CAN with $0.1 \%$ (V/V) TFA (mobile phase A) and 95\% (V/V) ACN with $0.1 \%(\mathrm{~V} / \mathrm{V})$ TFA (mobile phase B) were used to generate a gradient of $0 \%$ to $60 \%$ mobile phase $\mathrm{B}$ within $18 \mathrm{~min}$ at a flow rate of $1 \mathrm{ml} / \mathrm{min}$. All proteins were detected at $214 \mathrm{~nm}$.

\section{Template utilization efficiency}

Based on the definition of the template utilization efficiency $\left(E_{T U}\right)$ in our previous publications $^{2,3}$, the $E_{T U}$ was re-fabricated for the Multi-epitope templates imprinted particles:

$$
E_{T U}=\frac{\sum_{n=1}^{3} \frac{Q_{n, M I P s}-Q_{n, N I P s}}{M_{n}}}{\sum_{n=1}^{3} \frac{Q_{n, T}}{M_{n, T}}}
$$

where $Q_{n, M I P s}(\mathrm{mg} / \mathrm{g})$ and $Q_{n, N I P s}(\mathrm{mg} / \mathrm{g})$ are the adsorption capacities of MIPs and NIPs toward the target, i.e., epitopes or proteins. $M_{n}$ is the molecular weight of the target. $Q_{n, T}(\mathrm{mg} / \mathrm{g})$ and $M_{n, T}$ are the initial amount and the molecular weight of the 
template. It should be mentioned that in this experiment, the adsorption capacities of MIPs and NIPs were the adsorption capacities of MIPs and NIPs toward their respective targets at $22 \mathrm{~h}$, where they were considered as the saturation binding. $M_{1}$ is $1124.41 \mathrm{~g} / \mathrm{mol}$ for the molecular weight of HSA; $M_{2}$ is $893.01 \mathrm{~g} / \mathrm{mol}$ for the molecular weight of IgG; $M_{3}$ is $943.22 \mathrm{~g} / \mathrm{mol}$ for the molecular weight of TRF. According to the binding toward the templates, the template utilization efficiency was calculated as $38.2 \%$. This relative high template utilization efficiency was deductively contributed from the porous structures of PES particles and the small molecular weight of the peptides.

\section{Proteomic analysis and quantification}

9.1 Sample treatment

In the incubation with native human plasma, MIPs and NIPs were incubated with 3 $\mathrm{mL}$ native human plasma diluted 100 -fold at $4{ }^{\circ} \mathrm{C} .1 \mathrm{~mL}$ supernatant was collected from each sample and heated in a $90^{\circ} \mathrm{C}$ water bath for $30 \mathrm{~min}$. An $8-\mu \mathrm{L}$ aliquot of 1.0 M DTT was added to $1 \mathrm{~mL}$ of the diluted plasma. The protein solution was incubated at $56^{\circ} \mathrm{C}$ for $2 \mathrm{~h}$. Then, $20 \mu \mathrm{L}$ of $1.0 \mathrm{M}$ IAA were added, and the solution was shaken and kept in darkness for 30 min. $1 \mu \mathrm{L}$ ammonia water was added into the mixture to adjust the $\mathrm{pH}$ value. Trypsin solution $(1 \mathrm{mg} / \mathrm{mL}, 40 \mu \mathrm{L})$ was subsequently added to the mixture, which was incubated at $37{ }^{\circ} \mathrm{C}$ overnight. Prior to analysis, the digests were desalted with a C18 solid-phase cartridge.

For incubation with denatured human plasma, the plasma was first diluted 100 times and treated separately with DTT and IAA. Both MIPs and NIPs were then incubated 
with $3 \mathrm{~mL}$ denatured human plasma at $4{ }^{\circ} \mathrm{C}$. The protocols that followed were identical to those for native plasma, as described above.

\subsection{RPLC-ESI-MS/MS analysis}

Peptide analysis was performed using RPLC-ESI-MS/MS on a Thermo Q Exactive Orbitrap. A $15-\mathrm{cm}$-long capillary (75 $\mu \mathrm{m}$ i.d.) with a pulled spray tip was packed with C18 particles $(5 \mu \mathrm{m}, 300 \AA, \mathrm{XBP})$ at $5-6 \mathrm{MPa}$ by a gas pressure pump overnight. Meanwhile, a 2-cm-long capillary $(150 \mu \mathrm{m}$ i.d.) packed with the same particles was prepared as the pre-column. ESI voltage was set at $3.0 \mathrm{kV}$ for the LTQ-Orbitrap, and the spray capillary was heated to $250^{\circ} \mathrm{C}$. Total ion current chromatograms and mass spectra ranging from $\mathrm{m} / \mathrm{z} 300$ to 1800 were recorded using the Xcalibur software. The MS acquisition cycle was set as one full MS scan followed by 10 MS/MS scans. The dynamic exclusion function was set as follows: repeat count, 1; exclusion duration, 40 s. The MS/MS collision energy was fixed at $25 \%$. The resolution for the full MS was 70,000. Fragment ions were detected at a resolution of 17,500 . The two mobile phase solutions were (A) $\mathrm{H}_{2} \mathrm{O}$ with $2 \%(\mathrm{v} / \mathrm{v}) \mathrm{ACN}$ and $0.1 \%(\mathrm{v} / \mathrm{v})$ formic acid and (B) ACN with $2 \%(\mathrm{v} / \mathrm{v}) \mathrm{H}_{2} \mathrm{O}$ and $0.1 \%(\mathrm{v} / \mathrm{v})$ formic acid. The gradient was set as follows: $0-5$ $\min , 2 \%-5 \%$ B (v/v); 5-100 min, 5-35\% B (v/v); 100-110 min, 35-80\% B (v/v); 110$120 \mathrm{~min}, 80 \% \mathrm{~B}(\mathrm{v} / \mathrm{v}) ; 120-150 \mathrm{~min}, 2 \% \mathrm{~B}(\mathrm{v} / \mathrm{v})$. The flow rate was $300 \mathrm{~nL} / \mathrm{min}$ during the entire separation process.

\subsection{Data processing and analysis}

Tandem mass spectra were extracted from raw files using pExtract software [46] to single *.mgf, and then the *.mgf file was searched against the human International Protein Index (IPI) database (version 3.87) with a total of 91,464 protein entries using 
the Mascot server (v2.4.0) (Matrix Science, Boston, MA, USA). Mascot's automated decoy database was employed. Trypsin was set as the enzyme for database searching with a maximum of two missed cleavage sites allowed. Carbamidomethylation $(+57.02146 \mathrm{Da})$ on cysteine was considered as a static modification, and oxidation $(+15.9949 \mathrm{Da})$ on methionine was set as a variable modification. The mass tolerances were $10 \mathrm{ppm}$ for parent ions and $0.05 \mathrm{Da}$ for fragment ions. All identified proteins with FDR $<1 \%$ were considered as significant. Require bold red was also selected to improve protein significance. Peptide assignment to protein groups was done according to the Mascot default settings. Spectral count (SC), which accumulates the total number of spectra attributed to a protein, was applied as the quantitative measure of protein abundance in this study to evaluate the changes of the top three highabundance proteins in plasma proteome after treatment with NIPs and MIPs. For proteins with multiple forms identified, only the top-scoring form was considered. ${ }^{4}$ It should be mentioned that the spectral counts of all $\operatorname{IgG}$ proteins were summed with duplicated spectral removal, owing to the inability of determining the origin of each identified subunit.

\section{Quantification of proteins bound by MIPs and NIPs}

A label-free quantitative method, spectral counting, ${ }^{5}$ was used to quantify the captured protein amount (Figure 3). The binding amounts (spectrum counts) of ten highly abundant proteins by MIPs and NIPs were listed as followings:

Table S-2. Binding amounts (spectrum counts) of ten highly abundant proteins by MIPs and NIPs in the native and denatured human plasma samples. 


\begin{tabular}{|c|c|c|c|c|c|}
\hline \multirow{2}{*}{$\begin{array}{l}\text { Protein } \\
\text { Number }\end{array}$} & \multirow{2}{*}{$\begin{array}{l}\text { Protein } \\
\text { Name }\end{array}$} & \multicolumn{2}{|c|}{$\begin{array}{l}\text { Native human } \\
\text { plasma samples }\end{array}$} & \multicolumn{2}{|c|}{$\begin{array}{l}\text { Denatured human } \\
\text { plasma samples }\end{array}$} \\
\hline & & MIPs & NIPs & MIPs & NIPs \\
\hline P1 & HSA & 376 & 125 & 422 & 391 \\
\hline P2 & TRF & 41 & 7 & 84 & 60 \\
\hline P3 & $\operatorname{IgG}$ & 70 & 30 & 96 & 89 \\
\hline P4 & $\begin{array}{l}\text { KRT1 keratin } \\
\text { type II cyto- } \\
\text { skeletal } 1\end{array}$ & 15 & 15 & 3 & 2 \\
\hline P5 & Macroglobulin & 21 & 6 & 37 & 28 \\
\hline P6 & $\begin{array}{l}\text { Fibrinogen- } \\
\text { alpha }\end{array}$ & 38 & 10 & 23 & 21 \\
\hline P7 & $\begin{array}{l}\text { alpha-2- } \\
\text { glycoprotein }\end{array}$ & 64 & 29 & 38 & 39 \\
\hline P8 & $\begin{array}{l}\text { alpha-1- } \\
\text { antitrypsin }\end{array}$ & 31 & 21 & 26 & 17 \\
\hline P9 & $\begin{array}{l}\text { complement } \\
\text { C3 }\end{array}$ & 43 & 9 & 9 & 7 \\
\hline P10 & $\begin{array}{l}\text { apolipoprotein } \\
\text { A-IV }\end{array}$ & 1 & 2 & 9 & 12 \\
\hline
\end{tabular}

\section{Application for the depletion of the high abundance proteins in the human plasma}

For the application of MIPs to deplete the high abundance proteins in the human plasma, 8 MIPs and 8 NIPs were incubated with $3 \mathrm{~mL}$ above-mentioned denatured human plasma at $4{ }^{\circ} \mathrm{C} .1 \mathrm{~mL}$ supernatant was collected from each sample, $1 \mu \mathrm{L}$ am- 
monia water was added into the mixture to adjust the $\mathrm{pH}$ value. Trypsin solution (1 $\mathrm{mg} / \mathrm{mL}, 40 \mu \mathrm{L}$ ) was subsequently added to the mixture, which was incubated at $37^{\circ} \mathrm{C}$ overnight. Prior to analysis, the digests were desalted with a C18 solid-phase cartridge.

Peptide analysis was performed using RPLC-ESI-MS/MS on a Thermo LTQ mass spectrometer. A 15 -cm-long capillary ( $75 \mu \mathrm{m}$ i.d.) with a pulled spray tip was packed with $\mathrm{C} 18$ particles ( $5 \mu \mathrm{m}, 300 \AA, \mathrm{XBP})$ at 5-6 MPa by a gas pressure pump overnight. Meanwhile, a 2-cm-long capillary $(150 \mu \mathrm{m}$ i.d.) packed with the same particles was prepared as the pre-column. ESI voltage was set at $2.8 \mathrm{kV}$ for the LTQ, and the spray capillary was heated to $200^{\circ} \mathrm{C}$. Total ion current chromatograms and mass spectra ranging from $\mathrm{m} / \mathrm{z} 300$ to 1800 were recorded using the Xcalibur software. The MS acquisition cycle was set as one full MS scan followed by $8 \mathrm{MS} / \mathrm{MS}$ scans. The dynamic exclusion function was set as follows: repeat count, 1; exclusion duration, $30 \mathrm{~s}$. The MS/MS collision energy was fixed at 35\%. The two mobile phase solutions were (A) $\mathrm{H}_{2} \mathrm{O}$ with $2 \%(\mathrm{v} / \mathrm{v}) \mathrm{ACN}$ and $0.1 \%(\mathrm{v} / \mathrm{v})$ formic acid and (B) ACN with $2 \%(\mathrm{v} / \mathrm{v}) \mathrm{H}_{2} \mathrm{O}$ and $0.1 \%(\mathrm{v} / \mathrm{v})$ formic acid. The gradient was set as follows: $0-5 \mathrm{~min}, 0 \%-10 \% \mathrm{~B}$ (v/v); 5-95 min, 10-35\% B (v/v); 95-100 min, 35-80\% B (v/v); 100-110 min, 80\% B $(\mathrm{v} / \mathrm{v}) ; 110-125 \mathrm{~min}, 0 \% \mathrm{~B}(\mathrm{v} / \mathrm{v})$. The flow rate was $300 \mathrm{~nL} / \mathrm{min}$ during the entire separation process.

Tandem mass spectra were extracted from raw files using pExtract software to single *.mgf, and then the *.mgf file was searched against the human International Protein Index (IPI) database (version 3.87) with a total of 91,464 protein entries using the Mascot server (v2.4.0) (Matrix Science, Boston, MA, USA). Mascot's automated de- 
coy database was employed. Trypsin was set as the enzyme for database searching with a maximum of two missed cleavage sites allowed. Carbamidomethylation $(+57.02146 \mathrm{Da})$ on cysteine was considered as a static modification, and oxidation $(+15.9949 \mathrm{Da})$ on methionine was set as a variable modification. The mass tolerance was $2 \mathrm{Da}$ for parent ions and $1 \mathrm{Da}$ for fragment ions. All identified proteins with FDR $<1 \%$ were considered as significant. Require bold red was also selected to improve protein significance. Peptide assignment to protein groups was done according to the Mascot default settings.

\section{References}

(1) Yang, K. G.; Liu, Z. B.; Mao, M.; Zhang, X. H.; Zhao, C. S.; Nishi, N. Anal. Chim. Acta 2005, 546, 30-36.

(2) Yang, K.; Liu, J.; Li, S.; Li, Q.; Wu, Q.; Zhou, Y.; Zhao, Q.; Deng, N.; Liang, Z.; Zhang, L.; Zhang, Y. Chem. Commun. 2014, 50, 9521-9524.

(3) Li, S.; Yang, K.; Liu, J.; Jiang, B.; Zhang, L.; Zhang, Y. Anal. Chem. 2015, 87, 4617-4620.

(4) Deng, N.; Zhu, G. J.; Chen, Y. B.; Wu, Q.; Liang, Z.; Sui, Z. G.; Zhang, L. H.; Yang, K. G.; Zhang, Y. K. Anal. Chim. Acta 2014, 826, 43-50.

(5) Liu, J.; Deng, Q.; Tao, D.; Yang, K.; Zhang, L.; Liang, Z.; Zhang, Y. Sci. Rep. 2014, 4, 5487. 